\title{
Modos de comunicação e práticas de leitura dos escravos do século XIX
}

\section{Modes of communication and reading practices of slaves in the 19th century}

Marialva Carlos Barbosa ${ }^{1}$

Resumo: $O$ artigo mostra alguns modos de comunicação dos escravos brasileiros do século XIX, dando ênfase, sobretudo, às práticas de leitura e de escrita desses atores sociais fundamentais da história do Brasil. Dividido em duas partes, procura inicialmente mostrar as habilidades orais cotidianas para, na sequência, a partir da pesquisa em fontes primárias, descrever as suas habilidades em torno da escrita e da leitura. Revela, assim, um pouco do mundo da comunicação e das práticas orais, de leitura e de escrita dos escravos brasileiros no século XIX.

Palavras-chave: oralidade; leitura; escrita; escravos; século XIX.

\begin{abstract}
The article shows some modes of communication of Brazilian slaves of the nineteenth century, emphasizing, above all, the reading and writing practices of these fundamental social actors in the history of Brazil. Divided into two parts, it initially seeks to show the oral skills of everyday life, to sequentially, from primary source research, describe their skills around writing and reading. It thus reveals some of the world of communication and oral practices, reading and writing of Brazilian slaves in the nineteenth century.
\end{abstract}

Keywords: orality; reading; writing; slaves; nineteenth century. 
O silêncio que produzimos em relação aos atos dos homens que viveram antes de nós e que tinham em nós a imagem de um futuro possível advém de muitas razões. Neste artigo, cujo objetivo é mostrar os modos de comunicação e as práticas de leitura e escrita dos escravos brasileiros do século XIX, o percurso se inicia pelo barulho, qualificado como ensurdecedor, que esses homens e mulheres faziam em torno dos lugares públicos em muitas cidades brasileiras.

Os ecos que, do passado, chegam até o presente mostram os muitos modos de comunicação desses que formavam, nos 1800, a maior parcela da população brasileira, mas que tiveram seus modos de comunicação, que incluíam não apenas a possibilidade leitora e letrada, mas a capacidade de manejar códigos escritos, por muito tempo relegados a um silêncio ensurdecedor, por mais paradoxal que possa parecer essa expressão.

Qual a razão de não considerarmos os modos de comunicação da maioria da população brasileira dos 1800? Poderíamos elencar variados motivos, mas é preciso chamar atenção para questões sintetizadas em três palavras: restos, testemunhos e valor.

Se a memória é a abertura mais importante para acessar o passado, o testemunho é prova viva da fiabilidade do passado. Há que se considerar, ainda, que históricos não são apenas os processos localizados no passado: histórico é tudo aquilo que, do passado, chegou até o presente.

Os testemunhos, que permitem a reinterpretação do passado, são de múltiplas ordens: textos documentais depositados em arquivos que guardam a memória de uma época; textualidades múltiplas que foram produzidas num mundo que hoje denominamos passado; restos de uma cultura material duradoura; imagens que teimam em perdurar em suportes diversos; memória viva de quem estava inscrito no passado e que atesta a sua existência pelo testemunho oral.

Há que considerar também que o passado só é acessível através dos rastros e restos que, como ação de comunicação de homens localizados nesses tempos pretéritos, chegaram até o presente. Rastros diversos, mas 
que precisam ser indiciariamente lidos para que a mensagem que eles contêm, muitas vezes de forma esparsa e imprecisa, seja interpretada.

Por último, há que se falar na questão do valor do conhecimento. Como enfatiza Agnes Heller (1993), o conhecimento é um valor próprio de cada época: sempre houve alguma coisa que não pode ser conhecida, conhecimento considerado maldito, coisa que nenhum mortal deveria saber. Alguns desses conhecimentos só afloram à superfície quando se alcança determinado grau de consciência histórica. Esse parece ter sido o processo que encobertou, por mais de um século, as práticas culturais letradas e leitoras dos escravos do século XIX.

O fato de enfatizarmos as práticas leitoras e letradas dos escravos não quer dizer que não se reconheça o que pode ser denominado "competências da oralidade”. Muito pelo contrário. Por essa razão, antes de ingressar no território das práticas de leitura e escrita dos escravos, convém mostrar dois cenários nos quais os modos de comunicação mais uma vez se destacam: o primeiro denominamos competências da oralidade e o segundo chamamos indícios de uma ordem letrada.

\section{Competências da oralidade}

Entre as muitas competências da oralidade, destacam-se técnicas de comunicação que faziam da memória lugar fundamental para a repetição de narrativas imemoriais. Ao pé do fogo, após um dia estafante de trabalho, homens e mulheres podiam se reunir para contar histórias e, através delas, relembrar uma terra que se constituía, sobretudo para os mais velhos, numa espécie de paraíso perdido. Mas podiam simplesmente conversar em alto e bom som. Contar histórias é a primeira das competências do mundo da oralidade.

Os negros gostam de reunir-se ao cair da noite ao redor do fogo, fumando, palestrando e gesticulando, em grande algazarra. As tarimbas, das quais cada uma mede 2,5 a 3 pés de largura são separadas uma da outra por uma divisão de madeira de 3 pés de altura, tendo na frente uma esteira ou cobertor para tapar a entrada do lado do corredor. As senzalas ficam abertas às 10 horas da noite, havendo até lá, um convívio misto nas mesmas. A 
um sinal dado por uma campainha, os homens e as mulheres se retiram, cada qual para sua habitação, e o guarda as fecha a chave, abrindo-as na manhã seguinte, uma hora antes de iniciar-se a tarefa diária (TSCHUDI, 1980, p. 56, grifos nossos).

Mas não era apenas nas senzalas que esse burburinho de vozes se fazia ouvir. Muitas regiões eram pontos de ajuntamento de escravos que, entre uma faina e outra, faziam ecoar sua presença pelos modos orais de comunicação. Como, por exemplo, os chafarizes. A hora de buscar a água era também o momento de colocar os assuntos em dia, de saber o que se passava na cidade, quando o tema principal girava em torno dos novos contingentes recém-chegados da África. Em 1828, o reverendo Robert Walsh assim descreveu o alarido de homens e mulheres em torno do chafariz da rua da Vala (atual rua Uruguaiana, no Centro do Rio).

Um dia estava olhando esse cenário extraordinário através das janelas do Convento de S. Antônio quando, de repente, toda a praça ficou em polvorosa. Os homens atiravam suas latas, as mulheres espirravam água para os lados e a polícia usava o chicote; todos brigavam, gritavam e riam na maior confusão (WALSH, 1985, p. 211, grifos nossos).

Em torno do chafariz se reuniam os libambos, escravos prisioneiros condenados a carregar água para as repartições públicas. Acorrentados pelo pescoço durante o dia, frequentavam esses locais caracterizados pela alta concentração de transeuntes. Era ali que os libambos entravam em contato com diversas pessoas, colhendo informações e levando-as até a cadeia, tornando-se "janelas da prisão" (ARAÚJO, 2008, p. 93).

Os modos de comunicação entre os escravos prisioneiros apontam para um pacto com a informação que estava ausente como possibilidade para muitos. Por solidariedade, se transformam em meios de comunicação para os que não podiam ver a luz do dia. Nesse caso, seus corpos e a tecnologia da voz eram a possibilidade de outros entrarem em contato com as novidades do mundo. Eram homens que alargavam o horizonte de visão (pela informação) para outrem, se constituindo em janelas que, da prisão, se abriam em direção ao que existia no mundo lá fora. 
Outra competência da oralidade era a musical. Improvisavam sons e acompanhamentos, fazendo das mãos instrumentos privilegiados para o batuque, e executavam músicas para serem publicadas, isto é, dirigidas a uma audiência que podia estar ou não participando diretamente da roda de cânticos e danças.

A comunicação criada oralmente é sempre orientada para outro, pressupondo uma audiência, um público externo àquele que fala e que é percebido como alguém que, mesmo estando ao largo do que executa os atos comunicacionais sonoros, é parceiro da cena dialógica que se estabelece. Diante da audiência e de suas reações, os atores da comunicação oral podiam mudar a intensidade do acompanhamento, os gestos da dança e mesmo os versos da música. Criava-se sempre uma composição partilhada.

Dir-se-ia que após os trabalhos do dia, os mais barulhentos prazeres produzem sobre o negro o mesmo efeito que o repouso. À noite, é raro encontrarem-se escravos reunidos que não estejam animados por cantos e danças; dificilmente se acredita que tenham executado, durante o dia, os mais duros trabalhos, e não conseguimos nos persuadir de que são escravos que temos diante dos olhos (RUGENDAS, 1972, p. 147, grifos nossos).

Nos movimentos dos corpos após o trabalho do dia, destaca-se a forma como executavam as danças. Animados, estabeleciam um diálogo capaz de convidar outros a participarem da mesma narrativa. A batida cadenciada das mãos era a comunicação de que o espetáculo de música e corpo iria começar. O batuque era dirigido por um "figurante" que assumia o papel de mestre de cerimônias, com a participação de outros que acompanhavam o canto com sons manuais e corporais. A repetição do refrão atesta a presença do diálogo na comunicação oral.

A dança habitual do negro é o batuque. Apenas se reúnem alguns negros e logo se ouve a batida cadenciada das mãos; é o sinal de chamada e de provocação à dança. $\mathrm{O}$ batuque é dirigido por um figurante; consiste em certos movimentos do corpo que talvez pareçam demasiado expressivos; são principalmente as ancas que se agitam, enquanto o dançarino faz 
estalar a língua e os dedos, acompanhando um canto monótono, os outros fazem círculo em volta dele e repetem o refrão (RUGENDAS, 1972, p. 147, grifos nossos).

Pelas possibilidades do aparelho tecnológico da fala - a boca -, transmitiam o código de uma cultura não letrada cuja competência também se fazia pela capacidade de transmissão de sentidos e da comunicação. O canto era acompanhado por ritmos que vinham do corpo e da boca e outros entendiam os sinais emitidos, podendo repetir o refrão, que fora memorizado em função da frequência com que o ato dialógico musical era executado.

Na cena descrita por Rugendas, sobressai a forma como o corpo participava dos atos de comunicação. Acompanhando o ritmo com as mãos ou chamando para a dança com o movimento das ancas, expandiam os enunciados da fala com gestos corporais. O corpo era lugar de armazenamento de uma informação cultural que podia ser reutilizada.

A música fazia parte, também, do mundo do trabalho. Os vissungos, cantigas africanas, serviam não apenas para ritmar as atividades, mas podiam se transformar em maneiras de estabelecer comunicações cifradas. A repetição do refrão de determinados versos podia ser usada, por exemplo, como senha para avisar os outros da aproximação do feitor. O som definia, assim, o ritmo do trabalho, comunicava algo que não podia ser diretamente dizível e transformava o momento livre em algo partilhado. A vida escrava se organizava de maneira particular em torno das práticas orais complexas de uma comunicação que fazia da música forma de sobrevivência.

Se, por volta de 1660, havia no Rio de Janeiro uma população de pouco mais de 3.850 almas, dentre as quais três mil eram indígenas, 750 portugueses e apenas 100 negros (ABREU, 1987), em 1799, a cidade já contava com 43.376 habitantes, sendo que, desses, 34,6\% eram escravos (KARASCH, 2000, p. 109). E esse número não cessaria de aumentar nas décadas seguintes. Em 1849, havia aproximadamente 80 mil escravos e a cidade, durante as três décadas anteriores, abrigara a maior população escrava das Américas. No período de 40 anos entre a vinda 
da Família Real (1808) e o fim definitivo do tráfico negreiro, em 1850, é introduzido mais de 1,4 milhão de escravos no Brasil, ou seja, cerca de $40 \%$ dos africanos desembarcados em três séculos de história do Brasil (MARCÍlLIO, 1999).

Gradualmente, observa-se, a partir de restos do passado, uma nova ordem comunicacional se impondo: a ordem letrada. Ainda que não tenha modificado substancialmente as práticas da maioria da população que fazia as cidades mergulharem no barulho ensurdecedor das ruas, onde se vendia de tudo e onde se registram sempre imagens do burburinho humano, há que se considerar que também os escravos passam a ser personagens desse cenário de práticas de comunicação. Como registro duradouro da segunda década dos anos 1800, observamos a construção paulatina e gradual da esfera letrada e leitora que resultaria na expansão exponencial dos periódicos por quase todas as províncias do país a partir de 1821. E, dessa ordem letrada e leitora, participam os escravos.

Das telas de Debret e Rugendas vemos surgir leituras em espaços públicos, letras impressas marcando carregamentos diversos ou fixadas como letreiros nas portas das boticas e barbearias. Vemos também o movimento dos alunos sacudindo seus escritos na festa de Santo Aleixo, padroeiro dos escolares. Vemos ainda uma menina branca indo em direção à escola, sendo acompanhada por uma pequena escrava que carrega o seu material escolar. Observamos o movimento no interior das residências quando, num quadro da intimidade do lar, escravos se distribuem pelo chão ao lado de uma mulher que costura e de uma criança às voltas com as primeiras letras de uma cartilha. Mas vemos, sobretudo, na cidade e nos campos, jornais, mapas, livros, uma multiplicidade de impressos tomando os espaços.

Na imagem de Rugendas Praia Rodrigues perto do Rio de Janeiro, ${ }^{2}$ dois homens brancos, aparentemente cientistas, estão acompanhados por dois escravos. O primeiro está de pé diante dos cativos enquanto o segundo está mais adiante, agachado no chão consultando uma obra. Pelo formato, pode-se supor que sejam mapas ou um compêndio científico.

2 Disponível em: https://bdlb.bn.gov.br//acervo/handle/123456789/19898. 
O mais importante é que o impresso, naquele ambiente selvagem e inóspito, era fonte de informação sobre o mundo que se abria a seus olhos.

Detendo-nos na imagem do homem que está ajoelhado no chão, observamos que folheia um grande livro à procura de alguma coisa enquanto o outro espera o término do seu gesto. Talvez buscasse a localização exata para onde desejava ir ou comparasse espécimes encontradas a olho nu com aquelas que estavam registradas no livro.

Na segunda imagem, também de Rugendas, Matosinhos, ${ }^{3}$ um grupo de viajantes trafega por uma estrada entre as montanhas de São João Del Rey. Um maneja um carro de bois enquanto outros seguem a cavalo e ainda outro a pé, puxando o seu burro carregado de fardos. $\mathrm{Na}$ direção contrária, ao cruzar este último, um homem tira o chapéu. A pé, acompanhando-o, um escravo, também cheio de fardos, para a fim de folhear um grande impresso que está na mão do homem que segue a pé. Ampliando-se o desenho, vemos que o negro aponta uma imagem. Talvez seja um mapa e esteja indicando uma localização.

Pouco importa se Debret e Rugendas viram mesmo essas cenas, se as vestimentas eram de fato aquelas, se o gesto que fez cada um desses personagens foi fielmente fixado pelos artistas viajantes ou ainda se havia um sentido crítico ao produzirem distorções nos desenhos de maneira intencional. O que interessa é perceber que, ao registrarem em diversas pranchas imagens de cadernos, livros, folhas escritas, romances, mapas e compêndios científicos colados aos corpos dos sujeitos, estavam mostrando uma nova ordem comunicacional que passava a existir. As letras manuscritas e impressas somavam-se aos modos orais de comunicar, ampliando-se as possibilidades tecnológicas do mundo da comunicação.

A experiência partilhada mesmo pelos que ainda não sabiam manejar o código letrado e escrito, como os escravos, ao viver num mundo no qual as letras assumiam, ainda que muito parcialmente, o lugar da voz, implicava uma participação de todos nesse mundo. Mesmo talvez sem saber decifrar o código comunicacional, os escravos na cena da Praia do Rodrigues tomaram conhecimento do novo artefato e viram nele uma

3 Disponível em: http://bdlb.bn.br/acervo/handle/123456789/423038. 
possibilidade de busca por algo. O mundo dos sentidos e das expectativas das práticas em torno dos impressos se alastrava.

Talvez seja por isso que, na prancha seguinte, no processo de se comunicar, o escravo torna-se personagem ativo na composição. Ele não está mais parado, à espera do gesto de leitura do personagem letrado: agora é ele que, diante do impresso, aponta e toca o livro, indicando a possibilidade de ser decifrador daquele código.

Assim, os escravos que esperam a decifração do texto na Praia do Rodrigues para completar suas tarefas formulam uma impressão sobre o gesto que se produziu na relação do provável cientista com o texto fixado materialmente no grande livro. Naquele impresso havia algo que permitiria o passo seguinte; nele se procurava alguma coisa passível de ser decifrada.

E, finalmente, ela é revelada. Ao apontar com o dedo a imagem que está fixada no impresso - seria um mapa? -, o escravo da cena seguinte não apenas reconhece a materialidade, mas é capaz de estabelecer um pensamento abstrato, relacionando a imagem a um lugar, a um código, a um sentido.

Observamos que a expansão do mundo dos impressos permite que vários grupos tomem contato com essas materialidades e de múltiplas formas, introduzindo-as direta ou indiretamente nos processos comunicacionais que realizam. Ainda que não fosse o modo dominante na comunicação, as letras escritas e/ou impressas vão assumindo um lugar simbólico nas ruas das cidades e na imaginação daqueles que são capazes (ou não) de decifrar aqueles códigos.

O mundo das letras impressas e os modos de leitura que se esparramam pela sociedade passam, assim, a fazer parte do cotidiano também dos escravos, que são apresentados agora como imersos em práticas de comunicação que deixam ver modos leitores e letrados. O mundo de que vamos nos ocupar agora. 


\section{Modos de comunicação e escravos}

Como homens de seu tempo, envoltos em uma atmosfera na qual as letras impressas passam a ocupar lugar central, também os escravos do século XIX eram leitores de múltiplas naturezas: leitores por saberem efetivamente ler e escrever, estando imersos em códigos de leitura e de escrita; leitores por escutarem os textos, os que eram diretamente lidos para eles ou os que se espalhavam pelos ambientes das casas de seus proprietários; leitores, enfim, por saberem o significado das letras impressas e por acompanharem as imagens de suas faces e corpos expostos com frequência nos periódicos que circulavam pelos campos e pelas cidades.

Muitos, entretanto, mesmo sem saber manejar os códigos escritos, eram letrados: sabiam contar; eram capazes de exercer o ofício de carpinteiro e pedreiro, para os quais é indispensável o conhecimento dos códigos numéricos; podiam ser vendedores; impressores; enfim, exerciam múltiplas profissões nas quais os códigos letrados eram fundamentais.

Mas mesmo os que não conheciam as letras impressas sabiam a sua importância. Afinal, o que lhes concedia a liberdade era um papel repleto de inscrições: a carta de alforria concedia a liberdade pela escrita. Portanto, a aspiração máxima de todos estava inscrita num simples papel sobre o qual se adicionava letras: o letramento se igualava à liberdade.

Através dos vestígios que o passado deixou inscritos no presente, podemos remontar a relação dos escravos com o mundo da leitura (e da impressão) no século XIX. Dos anúncios que os periódicos publicavam emergem textos procurando por aqueles que se rebelavam e fugiam. Nesses, as marcas de seus corpos e suas diversas aptidões são descritas para facilitar o seu reconhecimento: entre elas, figurava o fato de "saber ler e escrever".

Fugiu no dia lo. de abril, ao abaixo assinado, o escravo de nome Pio, com os seguintes sinais: mulato, cabelos corridos quase pretos, altura regular, cheio de corpo, nariz afilado, tem nas costas um sinal como queimadura e bons dentes; sabe ler e escrever e trabalha um pouco de alfaiate (GAZETA DE CAMPINAS, 28 abr. 1872, p. 4, grifos nossos). 
No anúncio, podemos observar que, ao lado das marcas corporais, algumas em decorrência dos castigos comuns no mundo do cativeiro, Pio sabia ler e escrever, conhecendo igualmente o ofício de alfaiate, para o qual era indispensável a capacidade de manejar códigos do mundo do letramento. Outros anúncios denotam, algumas vezes, as astúcias presentes nas suas falas quando diziam serem forros apesar de efetivamente ainda não serem. Alguns sabiam recitar versos e muitos carregavam papéis junto ao corpo.

Dizer ser de um mundo que efetivamente não era o seu: dar-se por livre, dizer que era forro, não era mentira, era possibilidade crível em função das suas habilidades cognitivas. Como poderia ser escravo alguém que sabia ler e escrever, que falava bem e muito bem explicado, que guardava muitos papéis nas algibeiras e que gostava de recitar versos?

Fugiu da cidade de Itapetininga o escravo de nome Luiz, cabra 22 anos, altura regular e corpulento, pés grandes, cabelos grenhos, olhos vivos e pequenos, falta de dentes na frente, sabe ler e escrever regularmente, fala bem e muito explicado, muito risonho e fica sempre com papéis nas algibeiras, gosta muito de recitar versos, é pedreiro e copeiro e costuma dizer que é forro, anda descalço. É de Macaé, Rio de Janeiro (CORREIO PAULISTANO, 18 ago. 1877 in SCHWARCZ, 1987, p. 141-142, grifos nossos).

Embora Luiz possua o código mais visível da escravidão - andar descalço, já que era proibido aos escravos usar qualquer calçado -, possuía muitos códigos do mundo do letramento: além de saber ler e escrever regularmente (será que lia sempre, com regularidade, ou lia com a aptidão dos letrados, isto é, com rapidez e correção?), gostava de recitar versos. Além disso, falava bem e muito explicado, o que denota mais uma vez a habilidade que possuía diante das palavras.

Se alguns carregavam papéis junto ao corpo, outros eram capazes de manejar máquinas fundamentais para o mundo tecnológico das cidades em meados do século XIX.

Escravo - fugiu de Bierrenbach \& Irmãos, de Campinas, no dia 2 de setembro deste ano, o mulato Rodolpho, de 24 anos, estatura média para baixo, corpo reforçado, fala bem, pisar firme [...] é muito ativo e inteligente, 
natural de Campos (RJ), professor chapeleiro, mas sabe coser em máquina de costura, tendo trabalhado com máquina a vapor no que é prático. Sabe ler (CORREIO PAULISTANO, 11 set. 1877 in SCHWARCZ, 1987, p. 142 , grifos nossos).

Rodolpho, jovem como Luiz, podia ser identificado por pisar firme. Além disso, falava bem, sendo "muito ativo e inteligente". Sabia ler e era "professor chapeleiro". O que cada uma dessas palavras indica sobre o mundo conceitual de Rodolpho?

O mulato sabia manejar máquinas, novidades tecnológicas do século XIX: a máquina a vapor e a de costura, o que o tornava muito mais do que mero chapeleiro. Fazer chapéus não é algo simples, mas ele era mais: era aquele que ensinava o ofício artesanal a outros com menos habilidade conceitual. Além disso, o fato de ser "inteligente" é uma das características destacadas para possibilitar a sua identificação.

A capacidade leitora e escriturária dos escravos, por vezes, é ainda mais evidente. Testemunhos escritos que perduraram no tempo podem indicar claramente o domínio sobre essa habilidade. O caso do pedreiro Claro Antonio dos Santos, descrito por Maria Cristina Cortez Wissenbach (2002), mostra a dimensão do envolvimento dos escravos com a escrita.

A escrava Teodora, ao passar em frente a uma casa que estava sendo assoalhada por Claro, vê casualmente que ele, em um momento de descanso, escreve nos fundos da residência; então, pede que ele, em troca de seis vinténs, lhe escreva cartas para o marido e para um filho. Ao todo, Claro escreve sete cartas para ela.

A primeira indica o sentido que a escrava tinha daquela prática de comunicação: pela escrita, talvez pudesse descobrir o paradeiro do marido, já que ela apenas vagamente intuía onde ele poderia estar. A escrita, além de ser um diálogo entre ela e o marido, como se estivessem entabulando uma conversa, era também a possibilidade de estabelecer uma conexão comunicacional para além de espaços restritos.

Mas era mais. A carta servia para contar histórias, realizar trabalhos de memória, enfatizar crenças, reafirmar promessas. Tudo isso numa 
escrita que só pode ser decifrada se lida, de novo, em voz alta. Os códigos da oralidade migravam para o mundo da escrita, criando um universo comunicacional de misturas entre práticas orais e universos letrados.

Meu Marido Snr ${ }^{\circ}$ Luis

Muito heide estimar que esta va achar voçé esteije com saude que meu deseijo voçe me mande contar para hande voçé esta morando. Quem me arematou foi um moçó muito rico de campinas o homem chama Marciano quina eu fis uma pormeça em comgo voçé não esta lembrado da pormeça que voçé que eu fis voçé não esta lembrado que voçé pai vendeu voçé para se lembra da pormeça que me avisou de noite eu estava dormindo. Rainha tem companheiro de fase pormeça e não compir e agora ella esta persa no mal e poriço facillital com santos e poriço voçé veija que a rainha e maior do mundo e esta persa no mal e não pode se salvar porque São Bendicto perdeu ella no mar não pode se çalvar e poriço eu não facilito com santos eu espero hinda compir ainda que esteja com cabelos bracos... (AESP, A Justiça versus Claro e Pedro, escravos do cônego Fidélis Alves Sigmaringa de Moraes, 1868-1872 in WISSENBACH, 2002, p. 114-115).

Os periódicos, vez por outra, também reproduzem cenas dos escravos leitores. A Revista Ilustrada, por exemplo, na edição de 15 de outubro de 1887, mostra uma imagem que revela as misturas nos modos comunicacionais e a capacidade leitora de muitos dos escravos que moravam nas cidades ou no campo. No desenho, 10 escravos formam uma roda em torno de um que tem nas mãos um exemplar do jornal O Paiz. Numa atitude de leitura, em pé, cercado pelos outros, esse escravo está lendo a primeira página do jornal. Na legenda, escrita sob a forma manuscrita, a explicação: "um fazendeiro também fez uma descoberta que o deixou embatucado! Um escravo lia no eito para os seus parceiros ouvirem um discurso abolicionista do Conselheiro Dantas". Os outros escravos que compõem a roda, sete homens, duas mulheres e uma criança, escutam boquiabertos. Apoiam-se nas enxadas e fazem (podemos supor) o mais absoluto silêncio. Escutam com atenção as palavras que, do mundo impresso, invadem o mundo oral (BARBOSA, 2010). 
A cena mostra, mais uma vez, uma prática de leitura dos escravos do século XIX e a possibilidade de serem, de fato, leitores dos jornais. Leitores de primeira natureza como o que ocupa o centro da roda, na leitura dirigida aos ouvidos dos que escutam. Leitores de segunda natureza como os 10 outros que, em atitude de espera, ouvem atentamente as palavras impressas que ecoam sob a forma de voz. E de terceira natureza para aqueles que, próximos ou distantes dali, sabiam que havia, no eito, escravos lendo notícias e o tipo de informação que receberam através dessas leituras.

Nesse mundo comunicacional caracterizado por misturas, há uma tripla economia da escrita. No texto da carta escrita por Cosme para a escrava Teodora, os modos orais prevalecem nas formas que habilmente são compostas como escrita. No texto do jornal lido pelo escravo anônimo, os modos impressos se transmutam em palavras que, sob a forma de som, invadem o universo oral/letrado dos que ouvem o discurso do conselheiro Dantas. E, finalmente, a legenda que completa a ilustração da Revista Ilustrada indica, pela via manuscrita, a forma escriturária dominante que, também lida, transforma-se em sons que se esparramam pelos ambientes.

\section{Muitos outros também escrevem}

Os indícios da capacidade de escrever dos escravos não se resumem às cartas que Claro escreveu para Teodora. Nos arquivos perduraram outras cartas escritas pelos escravos do século XIX. Esse é o caso da carta do escravo Arnaldo Rigão destinada ao seu senhor, Antônio Coelho, e datada de 6 de abril de 1862 .

Mêo Senhor Antônio Coelho

Rio 6 de abril de 1862

Será satisfação para sêo escravo se estas linhas o encontrar com perfeita saúde. Mêo Senhor pelo amor de vossos filhos the vou rogar que pela bondade de mêo Senhor tenha paciência com o sêo escravo Arnaldo pois mêo Senhor sabe bem a maneira que fui criado e hoje me vejo chicoteado 
todos os momentos não por faltas de minha parte pois quando ando em mandado não ando corro e assim mesmo não satisfaço aos mêos senhores' por isso peco a mêo senhor que tenha paciência em mandar procurar minha mai para pedir-lhe o dinheiro que ella tenha que eu cá arranjo o resto, e espero em Dêos ainda hir ahi para agradecer o bem que mêo senhor me faça, e peco mais a bencão de Senhora mai de mêo Senhor não s esqueça de Sêo Escravo muito Respeito Arnaldo Rigão (CARTA escrita pelo escravo Arnaldo Rigão na cidade do Rio de Janeiro em 1862 in OLIVEIRA, 2009, p. 212).

A carta, cujo objetivo central era solicitar que o senhor procurasse a mãe de Arnaldo para pedir-lhe dinheiro - certamente para comprar a sua alforria -, tem todos os indícios do letramento do escravo. Após um início no qual reproduz o modo dominante do começo das cartas, com uma frase indicando o desejo de encontrar o destinatário em perfeita saúde e que servia para introduzir o assunto central, Arnaldo não se ocupa inicialmente do propósito da sua carta. Relembra a sua obediência, pede a paciência do senhor e se aventura a descrever, ainda que brevemente, os castigos a que estava submetido. Nas astúcias de sua fala transbordada em letras escritas, refere-se com respeito à mãe de seu senhor, faz com que ele se recorde da forma como tinha sido criado. Todos esses argumentos permitem que ele peça que o senhor procure sua mãe.

Na expressão de seus sentimentos, deseja que Deus agradeça o bem que porventura o senhor lhe faça e também pede a bênção da mãe do senhor. Por último, pede que o senhor não se esqueça "desse seu escravo" e relembra todo o respeito que deposita no "seu senhor", afinal continuava "seu escravo".

A carta indica também certa proximidade que Arnaldo julgava ter em relação ao seu senhor, mas revela, sobretudo, os traços da oralidade presentes na forma escriturária como compôs seu texto. Por outro lado, observa-se também os códigos da escrita epistolar tanto na abertura da carta quanto no seu fechamento, quando Arnaldo se despede referendando o respeito que sente pelo senhor. 
$\mathrm{O}$ ato de escrever vai além do grafar um pensamento sob a forma escrita. Refere-se também a um conjunto de fenômenos históricos que pressupõe três dimensões. A primeira é a operação realizada pela mão ao traçar caracteres com a ajuda de um instrumento (no caso, a pena sobre o papel), supondo uma interação de comunicação que ultrapassa o presente e se dirige a um futuro presumido e também é capaz de alcançar outras espacialidades. A segunda se refere a um conjunto de condições e circunstâncias (biológicas, psicológicas, sociológicas etc.) inerentes à própria operação da escrita. E a terceira diz respeito ao resultado da operação. Cada um desses elementos é redefinido num momento sempre histórico (ZUMTHOR, 2009, p. 101).

Inicialmente, as palavras gravadas em uma superfície são aquelas pronunciadas em voz alta, referindo-se mais a uma superfície verbal factível do que a uma superfície escriturária. Só gradualmente a escrita se converte em composição, com um tipo de discurso do qual está ausente a sensação de quem efetivamente está falando em voz alta (ONG, 1987, p. 34).

Nas composições escritas pelos escravos, observa-se, em todos os exemplos, os fortes vínculos das palavras grafadas com a oralidade, o que faz, por exemplo, com que uma mesma palavra numa mesma composição assuma formas escritas diversas ao sabor da melodia da fala em determinado momento. Observa-se também, na escrita, o ritmo da leitura e as repetições próprias do texto falado, no qual a lógica de composição está diretamente relacionada à rapidez maior das pausas do pensamento.

Perdaõ

A muito tempo que tenho desejo de não existir pois a vida me hé aborrecida porem naõ existindo naõ será mais pois quem pode viver sem ter disgostos que vá vivendo. A Jaia Pombinha e toda família d'ella sou muito grato por isto pesso pelo amor de deus Perdão sendo que com esta vez é a $3^{\text {a }}$ que eu tenho entado contra minha existência porem quem naõ quer viver nem deve tomar vidro, e nem sollimão pois saõ lentos a quem tem a 
mor a vida muito addemirava me naõ receiar-se com meo gênio nao fazer um acerto para mim pois naõ acho doudice n'este proceder.

Não há tempo perder!!!!

Poz-me preciso declarar-me que nem fui eu, e nem sabedor daquele infaime papel, e n'elle achava-me inocente se faço esta declaração é para livrar que vão ao Inferno, estas almas que dispistarão suas conciencias!....

Não persuadaõ-se que eu fiz digo: que cometi este atentado, por temer o que esta va-se fazendo; pois para passar melhor, não havia que temer: as rasões saõ outras pois a sepultura será sabedora, e naõ este infaime lugar digo e naõ esta terra de vivos (TEXTO escrito pelo escravo Timóteo na cidade de Salvador em 1861 in OLIVEIRA, 2009, p. 212-213).

No texto escrito pelo escravo Timóteo em 1861, não há um destinatário explícito, uma vez que o propósito principal é produzir uma despedida duradoura. Sabedor de que a inscrição sob a forma de letras manuscritas era capaz de transpor o tempo, produzindo a perenidade da composição, Timóteo começa seu escrito com um título que resume claramente o propósito de seu ato: pedir perdão pelo gesto que faria na sequência.

Condensar o propósito da carta de despedida que produziu numa simples palavra revela o índice de letramento do escravo, que era capaz de produzir uma síntese interpretativa da escrita que seria composta. Perdão era o que desejava mesmo diante do ato de possivelmente pôr fim à vida.

Na sequência, expõe com clareza as razões de seu ato: há muito tempo tinha o desejo de não existir, pois a vida lhe era aborrecida. Não existindo, não teria mais desgostos. Em seguida, expressa toda a sua gratidão a "Jaia Pombinha e toda a família dela”. Faz, então, uma revelação surpreendente: aquela era a terceira vez que tentaria o suicídio.

Tecendo considerações quanto às formas como se poderia pôr fim à vida, Timóteo afirma não achar doidice nesse proceder e exclama: "Não há tempo a perder!!!”. Classifica seu ato e declara sua inocência de um infame papel; para ele, a terra dos vivos era "um infame lugar". Temia 
que sua alma fosse arder no fogo do inferno e procura, assim, justificar seu ato.

A carta de despedida de Timóteo tem todos os índices de um letramento complexo, já que as argumentações que produz mostram as formulações mentais que era capaz de elaborar. Vai enlaçando os argumentos numa rede textual, produzindo uma narrativa com começo, meio e fim ao mesmo tempo que demonstra conhecer claramente os sentidos presentes numa escrita na qual reconhecia a possibilidade de perdurar no tempo.

Apesar disso, estão presentes na escrita do escravo índices de oralidade que aparecem em todo o texto. Só lendo mais uma vez em voz alta, talvez da mesma forma como o texto foi produzido, podemos recuperar os desejos presentes numa composição cujo fim último é significar durando.

Gostaria de terminar este artigo com a transcrição de um pequeno trecho do relato do viajante Charles Ribeyrolles, que, em 1859, ao ver as senzalas que por aqui existiam, assim registrou suas impressões diante dos casebres onde "não se fala nunca do passado - que é de dor - nem do futuro - que está fechado", dizia ele. O que lhe causou mais estranhamento foi o fato de que, em todas as senzalas, casebres pequenos, sem janelas e com uma única abertura - a pequena porta de entrada -, houvesse sempre um fogo permanentemente acesso. O fogo, na percepção do estrangeiro, encardia o teto e as paredes, além de tornar o calor insuportável, mais insuportável ainda. Mas o fogo não se apagava nunca (e não podia se apagar). E destacava: "Nos cubículos dos negros, jamais vi uma flor: é que lá não existem nem esperanças nem recordações”.

O fogo permanentemente acesso era a forma como os escravos mantinham a sua mais complexa forma de comunicação. O fogo simbolizava a continuidade do grupo e suas origens num "ancestral fundador". O fogo permitia abrir a janela para que se encontrasse o caminho da comunicação entre o mundo dos mortos e o mundo dos vivos, o calunga. ${ }^{4}$

4 Sobre o tema, cf. "Calunga: a comunicação dos vivos e dos mortos” (BARBOSA, 2016). 
A alegria que Ribeyrolles não viu - já que, para ele, ela estaria sintetizada na flor - não estava na flor, mas no fogo. O fogo, como bem disse Robert Slenes (2011), era a flor. A possibilidade de estabelecer a maior comunicação entre todas: a comunicação com todos os outros que viveram antes e que são os ancestrais.

\section{Referências}

ABREU, M. de A. A evolução urbana do Rio de Janeiro. Rio de Janeiro: Inplanrio: Zahar, 1987.

ARAÚJO, C. E. M. de. O duplo cativeiro: escravos e prisões na Corte Joanina (Rio de Janeiro, 1790-1821). Revista do Arquivo Geral da Cidade do Rio de Janeiro, n. 2, p. 8199, 2008.

BARBOSA, M. C. Escravos e o mundo da comunicação: oralidade, leitura e escrita no século XIX. Rio de Janeiro: Mauad X, 2016.

História cultural da imprensa. Rio de Janeiro: Mauad X, 2010.

CHALHOUB, S. Visões da liberdade. São Paulo: Companhia das Letras, 1990.

HELLER, A. Uma teoria da história. Rio de Janeiro: Civilização Brasileira, 1993.

KARASCH, M. C. A vida dos escravos no Rio de Janeiro. Rio de Janeiro: Companhia das Letras, 2000.

MARCÍLIO, M. L. A população do Brasil colonial. In: BETHELL, Leslie (Org.). História da América Latina. v. 2: América Latina colonial. São Paulo: Edusp: Funag, 1999.

OLIVEIRA, K. Textos de escravos no Brasil oitocentista: os tempos de uma edição filológica e de uma antologia comentada de alguns fatos linguísticos. Revista de Filologia e Linguística Portuguesa. São Paulo: USP, n. 10-11, p. 189-220, 2009.

ONG, W. Oralidad y escritura: tecnologias de la palavra. Cidade do México: Fondo de Cultura Econômica, 1987.

RUGENDAS, J. Viagem pitoresca através do Brasil. São Paulo: Martins: EdUSP, 1972.

SCHWARCZ, L. Retrato em branco e preto. Jornais, escravos e cidadãos em São Paulo.

São Paulo: Companhia das Letras, 1987.

SLANES, R. W. Na senzala, uma flor. Esperanças e recordações na formação da família escrava. Campinas: Unicamp, 2011.

TSCHUDI, J. J. V. Viagem às províncias do Rio de Janeiro e São Paulo. Belo Horizonte: Itatiaia; São Paulo: EdUSP, 1980.

WALSH, R. Notícias do Brasil. Belo Horizonte: Itatiaia; São Paulo: EdUSP, 1985.

WISSENBACH, M. C. C. Cartas, procurações, escapulários e patuás: os múltiplos significados da escrita. Revista Brasileira de História da Educação, n. 4, jul.-dez. 2002.

ZUMTHOR, P. Falando de Idade Média. São Paulo: Perspectiva, 2009. 


\section{Sobre a autora}

Professora titular da Escola de Comunicação da Universidade Federal do Rio de Janeiro. Professora titular aposentada da Universidade Federal Fluminense. Membro do corpo docente permanente do Programa de Pós-graduação em Comunicação e Cultura da UFRJ.

Data de submissão: 27/12/2016

Data de aceite: 09/03/2017 